\title{
CHAPTER 13 \\ ESSENTIAL AND FUNCTIONAL ANALYSIS \\ OF REGIONAL ECONOMIC SYSTEMS \\ IN TERMS OF FOOD SECURITY
}

\section{Shaposhnykov K. S.}

Holovko O. P.

\section{INTRODUCTION}

The global problem of humanity in the twentieth century was the food crisis. World population is growing every year and by 2050, according to scientists, it will reach 9 billion. This creates a need for Food Safety Management. The priority of the global economy is to ensure food for all segments of the population. Solving this problem is a priority for every state. Only public authorities are able to create food funds effectively used for support of basic foodstuffs.

Integration of Ukraine's economy and the world necessitates the study of food security of the population by region and analysing effective management of regional economic systems. First, you must define basic concepts in the study area.

The concept of "region" has many meanings and is used in many sciences, history, geography, political science. Therefore, the definition of the region is not unambiguous reference and encyclopaedic publications that are universal, defining the region have different meanings. For example, in the Little Dictionary of Economics, region is treated as a "region, district, part of a country that is different from other areas of the set of natural and (or) historical, relatively stable economic and geographic and other features that often are combined with features of the national structure of the population"1.

Domestic and foreign scholars interpret the concept of "region" in different ways, but you can find definitions of common features, an area specialization, availability of economic ties. Definition of the term can be grouped into the following areas of research ${ }^{2}$.

\footnotetext{
${ }^{1}$ Knysh, Y. (2011). Genesis nature and content of the concept of "region" as an economic category. Efficient Economy, 11. URL: http://nbuv.gov.ua/UJRN/efek_2011_11_43

2 Voronkova, V. G. (2010). Regional-administrative management: a manual. Publishing house "Professional".
} 
So, in terms of economics, the region - a territory that is different from other events or on attributes, characterized by unity, integrity, relationship elements that are the natural result of its development.

The economy of the region is heterogeneous, and therefore, for the regional economic system will always be a characteristic level of differentiation of regional economic spaces, which is a natural phenomenon that makes a number of positive aspects in the development of regional economic systems, ensuring their original dynamism and competition. The disintegration of the economic space of the country, which finds expression in chaotic, uncontrolled self-development regions, neglecting the national interests and breaking the inter-relationships is a typical consequence of regionalization in terms of the weakness of the central government and regional policy uncertainty. Disintegration is the opposite phenomenon to regional integration, in which both positive and negative consequences can be noted. So, in the region, there are constant economic processes. These include the planning and forecasting of the economy, finance, banking and investment flows, legislative regulation, monitoring of natural and human resources, emerging food market. These are important food security issues in the concepts of national security. In connection with the desire to integrate Ukraine into the European community, the problem of regional food security becomes important.

\subsection{Food security in the structure of economic security}

Food security is an important part of economic security, which in turn is a part of social security. The central element of food security is the security of food and its structure should be divided into four components. Availability of food is found in three forms. Physical accessibility implies simple presence in the consumer market of essential products, economic accessibility includes the possibility of financial gain, and social - minimal differentiation in consumption of major food groups among the different populations ${ }^{3}$.

Many domestic and foreign scientists investigated and studied the features of food security; under the food security they understand the ecological and economic situation of the state in which all its citizens are provided with food in the required quantity, range, and the corresponding quality maintains the highest level of physical and mental health ${ }^{4}$.

\footnotetext{
${ }^{3}$ Manylich, M. I. (2004). The transformation of regional economic mechanism [monograph]. Chernivtsi Books.

${ }^{4}$ Matvienko, R. O. (2013). Economic system and its role in the regional space: specific elements. Actual problems of economy, 5, 152-155.
} 


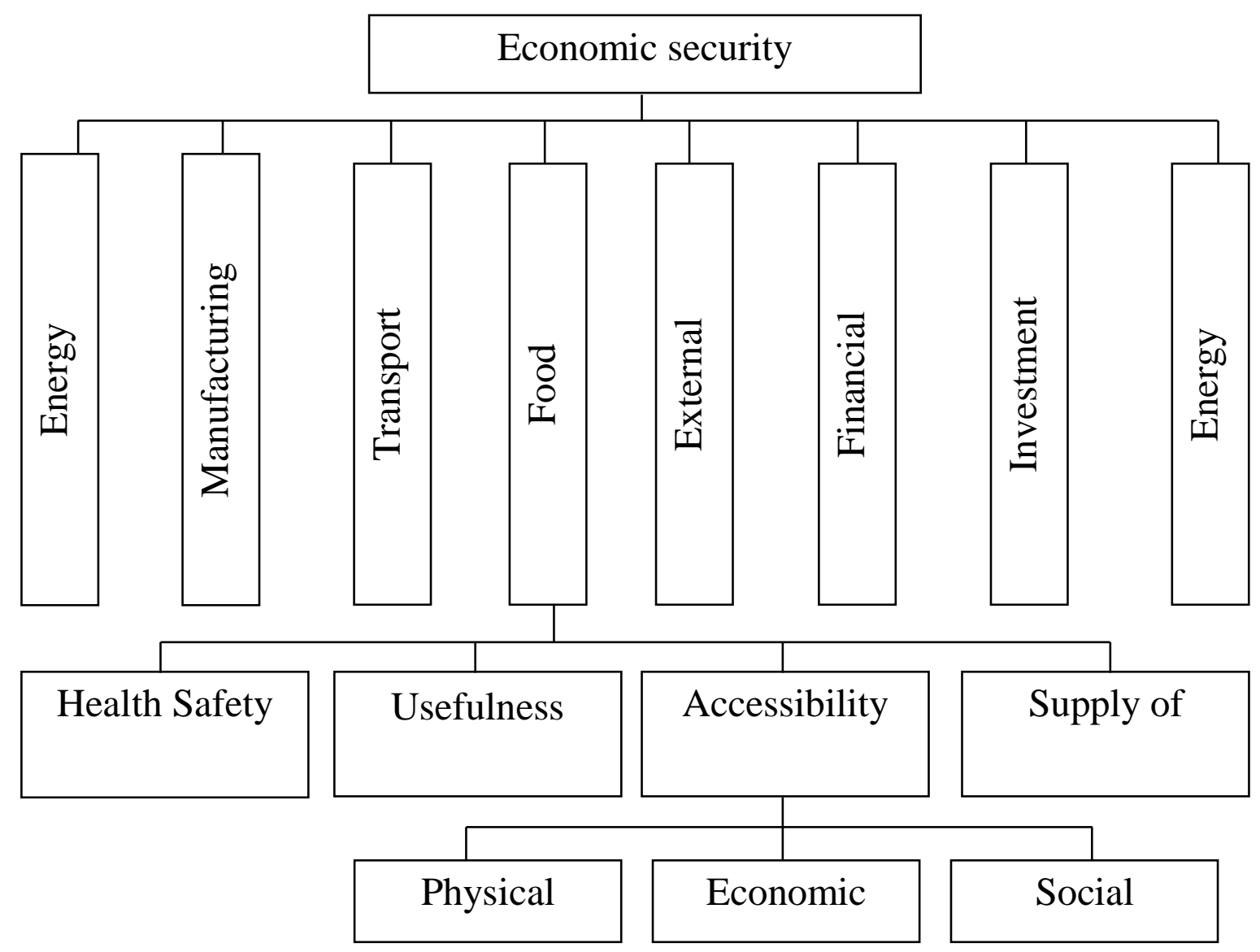

Fig. 1. Food security in the structure of economic security ${ }^{5}$

It is necessary to consider food security from the socio-economic and environmental side. Socio-economic content includes increased production or import food shortage, and its availability to the public. The environmental side includes adherence to the standardization of production, which ensures the safety of the environment. Food security is a multi-level structure.

The highest link - national food security - depends on its efficiency. This region forms the socio-economic system of the country, sets targets for improving the system of food security. At the same time, any region is relatively independent and geographically separate subsystem across the country, has an internal structure, especially the economy, resources and reserves, own goals and interests in economic development. Strengthening the role of the regions in implementing economic policy and food security is justified because it begins with the meso-level integration processes, formed the basis for socio-economic development, and lays the competitive advantages of the regions.

\footnotetext{
${ }^{5}$ Chechel, A. (2000). State regulation of food security. Economy of AIC, 8, 73-76.
} 
Ensuring effective functioning of the food security of the region depends on ${ }^{6}$ : ensuring stability subsystems; structural changes in agriculture; investment policy; forming subsystems logistics; improvement of tax legislation; banking service; creating inventories of material and technical means; the current system of insurance and property fields of agricultural enterprises; research and information support.

Food security in the region can be achieved if the following conditions are met:

- population provided with quality and safe health food produced by special norms and standards, according to the diet, age, gender, working conditions, climatic conditions, and national traditions;

- food prices accessible to all segments of the population, regardless of profession, age, family composition;

- funds set up food in case of famine, natural disasters, wars, and other emergencies;

- water and land craft developing steadily and have reserves of resources that allow increasing food production to refresh and replenish insurance reserves in case of assistance to other countries where the disaster happened or war;

- education and science are at the highest world technological advances. Innovative production technologies. High automation of production. The increased gene pool of livestock breeding and plant cultivation. Science predicts and gives advice on all areas of life and society in the future for intelligent control circuit;

- a policy of conservation and environmental remediation operates in practice and ensures the preservation and improvement of the environment.

The degree of food security in the region may assess describing the following parameters: public health; life expectancy, fertility and mortality; the presence of national and local development programs; the level of the population with food; state production; quality of food; availability of products; volume and increase of production capabilities in the event of natural disasters, wars, and other emergencies; the level of implementation of scientific and technological progress; ability to preserve the environment and improve the environment of the region.

Food security is a category of regional economy and management, as characterized by the level of resources, industrial and investment potential

\footnotetext{
${ }^{6}$ Ulianchenko, A. V. (2014) Food security - the basis of national security. Congress World. URL: http://humanright.org.ua/blogs/prodovolcha_bezpeka
} 
of the region and its efficient use and, at the same time, the degree of influence of destabilizing the region as a socio-economic system, the nature of the ties between the constituent elements of the regional economy, regional balance and foreign relations, efficacy mechanism of formation of commodity supply in the territorial food market.

To ensure food security, there is the need to develop regional development strategy, which would be based on the ratio of interest national and regional policies and the achievement of national, regional, and corporate goals.

\subsection{Strategic management of economic development, its characteristics, and role in shaping the competitive advantages of the region}

Globalization of the world economic processes enhances the role of competition between states and their territories. Modern management is a strategic impetus in the formulation, implementation, and realization of regional development strategy based on continuous monitoring and analysis of environmental change, which is used to support the region and ensure its support at the state level. Everything is the urgent search for new ways of regional development and competitiveness of regions.

Ensuring food security is a leader in economic growth strategies of developed countries. At present, all states with advanced market economies implement a program of national economic development strategy chosen by food security. The essence of strategic management is to implement long-term plans that reflect the end result and how to achieve it, involves the creation and development of a certain economic model that depends on external and internal factors.

Thus, strategic management of economic development of the region is a type of control, in which the operation target area focuses on the requirements, quickly adapting to the environment, selects the means to improve the competitiveness of the territory, as a result, and provides a stable development in the long run.

The strategic planning of regional development in Ukraine provided strategic and program documents of four levels: national, regional, subregional, and basic. At the national level, strategic development priorities for all regions of Ukraine are set by the State Regional Development Strategy for the period until 2020.

Formation of the economic development strategy of the region is important and causes interest to scientists. An important form of 
implementation of these aspects of regional development is strategic planning, which makes it possible to implement effective management of the region as a single organism and to ensure adequate living standards of its population. Therefore, it is necessary to pay attention to strategic planning, which is a natural step for the formation of local government, caused a crisis of centralized management, the rejection of direct regulation of the economy, reform of hierarchical relationships, resulting in increasing the level of autonomy and responsibility of local governments ${ }^{7}$.

Thus, strategic planning at the regional level is the process of setting goals and values of economic indicators for the most important areas of socio-economic development in the long term based on forecast of future state of the system, the formation of mechanism of implementation, and is a part of the State Administration of goals' achievement. The strategic planning process at the regional level includes the following steps.

Step 1. Strategic analysis. The essence of the first phase is to organize work on the analysis of socio-economic development and the development of planning documents. Strategic analysis is used to evaluate the impact of external and internal factors that have an impact on the development of the region that determines the choice of strategies and prospects of its implementation. Long-term development of the region largely depends on the achievements in the previous period and the state of efficiency of the social and economic potential of the region.

Step 2. Mission statement, goals and objectives of social and economic development. The mission must be socially significant. At this stage, it is important to identify the true desires, interests, and needs of the local community. Only socially-oriented plan or program would get public approval and support. At this point, a system of socio-economic development in the future. Based on the identified social and economic problems, to formulate long-term and short-term goals at every level of government in the region for all projects and programs. Goals should be formulated to keep the possibility of adjustment in case of change of external or internal conditions, under which achieving them is envisaged. Simultaneously goals should be acceptable for the main actors involved in their implementation. The level of property management to achieve sought by local governments must be realistic. Following the second phase of the formulated strategy of socio-

\footnotetext{
${ }^{7}$ Chechel, A. (2000). State regulation of food security. Economy of AIC, 8, 73-76.
} 
economic development, interested parties are discussing the received document, make corrections and comments. The agreed document is submitted for approval by the legislative branch.

Step 3. Justification and selection of the strategy. The third phase of strategic planning is directly linked with the development of a socioeconomic development strategy. It involves the creation and evaluation of alternative areas of regional development and the selection of the most preferred option. Formation and evaluation of alternatives in the region represent a value itself for management and implementation of a strategic planning process. It highlighted time frames, activities, resources, volumes, and sources of funding and those responsible for the implementation of planned activities.

Step 4. Development of predictive analytical documentation. On the fourth stage, justified the choice of forecasting and analytical document of strategic development of the region developed. The predictive analytical instrument developed is an instrument of policy implementation regulator; reveals the goals and directions of its development; defines the stages of socio-economic development of society as a whole and its individual subsystems; serves as a measure, the criterion of economic and social progress of society. It justified the specific digital content and relevant forecasting calculations based on internal activities of the region. This calculation is performed for multivariate forecasts, and the most effective strategic alternatives are selected.

Each region has its own characteristics in the development of strategy and management. Regional strategic management had focused on achieving goals in an unstable, competitive, market environment, which includes a diagnostic analysis of the region, strategic planning, and implementation of the chosen strategy.

The first phase of the lifecycle of the region (recovery) involves a fracture of the negative trends prevailing in the socio-economic development of the region and achieving a quantitative pre-crisis level of the most important products in different sectors. The main objective of this phase - ensuring the quality of life of the region in accordance with the accepted norms and standards. In this phase, the industry producing consumer goods and medical services should get priority development. A group of industries, some industries and companies that produce products for industrial purposes and provide quantitative growth, the region in individual sectors, and science and education and utilities get support selectively. High-tech production due to limited resources gets 
support for individual industries and companies that provide national security and lay the foundation for further qualitative structural changes in the economy. And individual enterprise sphere of culture and leisure will precisely receive support.

The second phase of the lifecycle of the region (growth) - further quantitative growth of the regional economy and its individual sectors over the level that was achieved before the crisis. The main objective of phase - full and effective use of available natural resources of the region. In this phase, the priority development cycles get energy-field region, providing output for industrial purposes, science and education, and utilities. Selective support is given to certain sectors of the agriculture, energy, and health sectors, and some support - individual companies of the same sectors in the region. High-tech production, culture and leisure sector will receive some support.

The third phase of the lifecycle of the region (namely development) large-scale development of new technologies, qualitative change in the economic structure of the region, enhancing its competitiveness and efficiency to the world average level parameters. The main objective of phase - providing quality structural changes in the economy of the region. In this phase, high-tech industries will receive priority development, as well as culture and leisure. Some energy-industry cycles, producing products for industrial purposes, science and education, and utilities are receiving selective support.

Competitive advantages of the region are characterized by certain conditions that distinguish it from other regions. The successful development and implementation of effective strategies of regions more and more depend on the unequal distribution of resources described above.

At present, the main task is to develop a regional strategy for regional competitiveness - its formation, maintenance, and continuous strengthening. The competitiveness of the region includes the concept of risk as the most important characteristics of business processes in the region because competitive position and characteristics of competitiveness as a set of potential include the study of risk inherent in this region.

\subsection{Priorities of regional development in terms of food security}

Analysis of regional strategies found that all regions and subregions of Ukrainian Black Sea Region singled out agriculture, transport and 
logistics, tourism and recreation as priority areas. The development of innovation as a strategic priority is provided by strategies of Kherson and Odesa sub-region. Priority development of social policies present at the regional level and at the subregional level - a priority for human development, which aims to enhance the professional skills of people and their cultural development. At the regional level, priority development of industries is identified, and at the subregional level small and medium businesses.

Among the priorities of development and strategic planning, the European integration processes should be highlighted:

- Euroregion. The border regions of Ukraine, involved in the operation of eight Euroregion - Bug, Carpathian, Lower Danube, Upper Prut, Dnipro, Sloboda, Yaroslavna, and Donbas. It is composed of Volyn, Donetsk, Zakarpattia, Ivano-Frankivsk, Luhansk, Lviv, Odesa, Sumy, Chernivtsi, Chernihiv, and Kharkiv regions of Ukraine;

- Border Cooperation Program implemented using the ENPI (European Neighbourhood Instrument (ENI)) for 2014-2020 (budget of $€ 15.433$ billion). European Neighbourhood provides for the following areas of cooperation between the countries as economic development, security, and migration.

One of the programs funded by the European Neighbourhood is a program of Black Sea Border Cooperation for 2014-2020 (Black Sea Basin, 2014-2020). The purpose of this program is to improve the welfare of the Black Sea region by means of sustainable economic growth and joint protection of the environment ${ }^{8}$.

The main outcomes of partnerships of the Black Sea region of Ukraine with the EU member states should include:

- developing interregional cooperation potential of Ukrainian coastal regions and introducing an intensive model of economic growth based on the diversification of resource sources;

- viewing the status and role of the coastal regions of Ukraine in the international division of labour; revival and further development of the Ukrainian Black Sea Region as an international recreation area (spa treatment, rehabilitation, recreation) and tourism;

- ensuring integrated and sustainable spatial development of Ukrainian coastal regions;

\footnotetext{
${ }^{8}$ Coastal, V. K. (2011). Issues of Ukrainian food security. Economy of AIC, 5, 71-78.
} 
- commitment to environmental security and the ability to heal the natural resource potential.

Food safety management strategy is linked to the regional economic strategy and relevant agricultural policy. National Strategy provides the distribution of resources between regions to achieve its goals and objectives, and regional policy defines these necessary resources to facilitate the achievement of objectives. Forming the strategy of food security in the region, in our opinion, should be associated with the agricultural sector development programs, socio-economic development, and environmental security of Ukraine. But not only resources are the subject of competitiveness. In terms of regional unevenness, it is extremely important to ensure the competitiveness of certain industries. Their socio-economic objective is to create economic food availability, increase purchasing power.

According to the above, one can generate the following areas of food safety assessment of regions ${ }^{9}$ :

1. The market balance of production and supply of foodstuffs, which is based on the study of consumption and domestic trade between regions producing regions and consuming in terms of: the types of food; the adequacy of nutrition in accordance with the physiological needs of the population; the supply channels (detailing the biggest suppliers).

2. Ranking of regions, the contribution of each to the overall state or "ensure" food supplies within the relevant industry clusters. This food security dimension deeper reveals its essence as a component of economic security. The proper level of food security depends on the social and economic stability of industrial centres and efficiency of large enterprises, so the evaluation of reserves to ensure their food security needs characterizes the state in connection with its economic interests and national security;

3. The economic accessibility of food to be characterized by: comparing the overall level of income and the level of prices for basic foodstuffs; the adequacy of funds to ensure household nutrition in terms of gender and age structure, belonging to a group of physical activity. This dimension of food security assessment characterizes the region's food security as a part of proportion to the whole population of the region in the total population of Ukraine.

\footnotetext{
${ }^{9}$ Germanenko, L. M. (2015). Food security in the region as a prerequisite for national food security. Bulletin of the Eastern University of Economics and Management. Series: Economics and Management, 1, 20-27.
} 
Characteristics of competitive advantages and limitations of perspective development of the region, the development of a strategic plan based on the diagnosis are starting conditions for regional development analysis by SWOT $^{10}$.

The competitiveness of the region reflects a set of comparative advantages in different areas (economic, investment, innovation, technology, personnel, market, etc.), the combination of which forms a strong regional position in comparison with others. Regional competitiveness is formed through the effective and efficient use of production, marketing, financial, scientific, technical, and human resources.

For the successful implementation of the management strategy of regional economic development, it is needed to create actual models that function effectively. In the current context of globalization, such a model should take into account the historical features of the region, resource potential, the principles and methods of management of economic, financial, social, and organizational aspects of economic activity and more. Formation of regional development paths requires the development of appropriate models and modelling processes.

Scenario development strategy is a description of the sequence of events from the present to the future status of the region based on assumptions. The main types of scenarios are ${ }^{11}$ :

- likely scenario based on maximum use of the strengths and opportunities;

- threat scenario based on the maximum weaknesses and threats, without exerting crucial strengths;

- other versions based on different relationships.

The strategy of economic development based on the model of regional development - the totality of views on ways to address socioeconomic problems, goals and implement challenges of the region in the future.

The model of economic development is the main vision of the economic development of regions and the country as a whole, proposed for implementation by the authorities and local governments. Features of models of economic development specific conditions defined relationship and interaction of economic factors. Models of

\footnotetext{
${ }^{10}$ Guidelines for the formation of regional development strategies (2002). Ministry of Economy and European Integration.

${ }^{11}$ Osipov, V. M. (2014) Priorities for socio-economic development of Ukrainian context of modern regional policy. Prometheus. Transformation and prospects of development of local systems, 2(44), 76-82.
} 
economic development are based on theoretical laws of functioning of economic entities in the market system. Specific conditions in different countries and regions determine the specific relationship and interaction of economic and other factors as the degree of achievement of economic goals, and hence especially the development of national and regional models.

Each regional model of strategic management has certain generalizations that reflect the trends of the economic system. It is, therefore, necessary to consider the principles, which formed the model and strategic management.

Characteristic patterns of regional economic development define: economic resources, regional characteristics, the nature of the economy, the level of economic development in the country and the world, institutional and sectoral structure of the economy, the role of economic agents, the system of state regulation of the economy, openness of the economy and the degree of involvement of economic relations, the use of foreign capital. According to the temporal stages of development, the dynamics of these characteristics are considered. In models of integration groupings, focuses are on the purpose and tasks of groups, organizational structure and resources, role and place in the global economy, prospects and problems, development programs ${ }^{12}$.

Each region of the state has economic potential, creates and manages its own budget funds, and organizes financial, resource, commodity exchanges within the region or exchanges with other regions, decides on production, investment, employment, and social problems within the territory.

Clusters are one of the most common worldwide models of successful economic development at the regional level. The development of regional industrial clusters is now a widely accepted tool that enhances the competitiveness of the economy. A growing number of cluster associations in countries confirmed their effectiveness. Today, in Ukraine, there are about 50 clusters in different regions and sectors. Among them is the southern region, which includes Odesa, Mykolaiv, Kherson regions.

The southern region has many competitive advantages among others, namely transport system (extensive river system, the Black Sea,

12 Zhavoronkova, G. V. (2010) Strategic Regional Development. Problems of environmental biotechnology, 1, 26-31. 
important logistics centres) territorial and sectoral proximity, investment attractiveness, the presence of a strong scientific and technical base.

In carrying out simulation and selection of management strategy of regional economic development, Ukrainian Black Sea Region should be guided by the provisions of the State Regional Development Strategy by 2020 , taking into account the priorities of regional policy, namely ${ }^{13,14,15}$ :

1. Interterritorial cooperation.

2. Participatory democracy.

3. Interregional cooperation of Ukrainian Black Sea regions.

4. Balanced spatial development at the "city and suburban area rural area".

Results of the study are as follows ${ }^{16}$ :

1) social component, present in all policies at the regional level, at the subregional level the priority is human development;

2) interterritorial cooperation, not mentioned in any strategy at the regional level, is the main component of sub-strategies, the main principle of their design and implementation;

3) development tools of the business environment and innovation sphere, provided in all policies, but the policies' subregional data tools are applied in nature and more adapted to implementation in practice;

4) consideration of regional (sea) specificity;

5) development tools in small towns and villages, little attention is paid to municipalities in strategies of Mykolaiv and Kherson regions;

6) cross-sector partnership.

The southern region, which formed a cluster model, has certain advantages, namely ${ }^{17}$ :

- efficient use and development of the economic potential of the region to attract resources from inefficient industries;

- establishing contractual cooperative relations between business, government, education and science, providing a synergistic effect;

\footnotetext{
${ }^{13}$ Fetisov, G. G. (2006). The regional Economy and Management: Textbook. INFRA-M.

${ }^{14}$ Kozlovsky, S. V. (2012) Tools of food security and social protection crisis in terms of economies. Crimean Economic Bulletin, 1(01), 266-269.

${ }^{15}$ Romanko, A. P. (2015). The concept of regional competitiveness and its features. Efficient Economy, 3. URL: http://www.economy.nayka.com.ua/?op=1\&z=3869

${ }^{16}$ Panuhnyk, O. V. (2011). Methodical maintenance of strategic planning in the regions of Ukraine. Actual problems of Economy, 1(91), 152-157.

${ }^{17}$ Stepanova, K. V. (2016) Ukrainian Black Sea Euro-regional cooperation system. Socio-economic problems of the modern period in Ukraine. Institute of Regional Studies NAS of Ukraine, 3(119), 135-139.
} 
- improving the competitiveness of cluster members, increasing their market share through mutually beneficial cooperation, particularly in marketing, exchange of scientific and technical research and innovation;

- strengthening of specialization and division of labour between members of the cluster, which allows reducing the cost of production and increasing its competitiveness;

- creating terms of economic growth, promoting scientific and technological progress, increased innovation production;

- increase in domestic and foreign investment, export growth;

- creation of new high-paying jobs, promotion of healthy social capital, and management of regional business elite;

- reducing unemployment and expanding the tax base;

- improvement of people's lives.

Even though cluster technology has several advantages and prospects, there are problems that prevented them from large-scale and efficient use. The main problems according to scientists include ${ }^{18}$ :

- lack of awareness of government and business representatives in the application of the cluster approach;

- lack of public policies that ensure a systematic approach and coordination of various levels of government in the implementation of cluster projects and as a result - the lack of organizational and financial support of cluster initiatives;

- lack of trained specialists on issues related to cluster organizational technologies;

- lack of an effective methodological framework that provides the application of cluster technology.

Thus, the cluster model solves most problems of socio-economic areas, regional development aimed at improving infrastructure and investment, thus increasing the number of jobs and increased employment.

Of course, it takes time and thorough scientific study to realize that clustering - a streamlined method of interaction between government and business, it is more dynamic, faster, more efficient but, at the same time, more complex. Cluster development is geographically dispersed; it is quite a complex process of interaction where the private business

\footnotetext{
${ }^{18}$ Gornyak, A. V. (2016) Estimation food security at regional level. Bulletin of the Odessa National University. Economy, 10(52), 17-21.
} 
has a significant voice. For clustering in Ukraine, a development strategy should be elaborated; we actively promote the concept of clusters to improve the conceptual basis to improve the economic stability of the state.

\section{CONCLUSIONS}

1. Scientists show the world that even in the twenty-first century, there is hunger and malnutrition. Overcoming these negative phenomena in society is possible by the intensification of food security. Every country in the world should form a reserve of food, to ensure the availability and quality of products. The primary task of the state and regional authorities is to ensure equal conditions for the functioning of the food market, avoiding its monopolization, to promote the development of small producers.

2. Strategic planning of regional food security advocates integrating force of the region and creates, organizes, and directs the process of equitable distribution of resources at the territorial level. In addition, strategic planning creates the conditions necessary to overcome the regional problems of economic development and provides interaction of state and local authorities, in particular, in the context of the implementation of regional development programs. The strategic vision of the region is to determine its place in the state at different rates, the ups and downs in development, evaluate opportunities and create new conditions for development, encourage innovation processes in time to determine changes in the internal and external environment and respond quickly to them.

The impact of the implementation of regional development strategy and the timely execution of tasks of the regional development program in the context of competitive advantages depends not only on the availability of resources, population, and investment but also on the management efficiency. Therefore, to ensure food security in the region strategic development programs are developed and implemented to expand and strengthen competitive positions of the region and state.

3. Building, implementing, and effective managing a unique model of regional development is a strategic task of the government. Management model should meet the main bases and principles of the 2020 National Strategy of Regional Development, which is a national model of achieving the goals, trends, and patterns of development, the definition of strategic priorities of the state and social policies, 
industries, agriculture, investment and innovation, the identification of steps and mechanisms of their implementation.

Modelling of regional development includes the development and implementation of institutional and economic mechanism based on subsidiarity, public-private partnerships, etc., providing for the introduction of public-public and public-business initiatives for the effective use of financial and economic instruments of state regional policy.

\section{SUMMARY}

The article deals with food security that is an important part of economic security, which in turn is a part of social security. It is necessary to consider food security from the socio-economic and environmental side. Socio-economic content includes increase production or import food shortage, and its availability to the public. The environmental side includes adherence to the standardization of production, which ensures the safety of the environment. Food security is a multi-level structure. Every country in the world should form a reserve of food to ensure the availability and quality of products. The primary task of the state and regional authorities is to ensure equal conditions for the functioning of the food market, avoiding its monopolization, to promote the development of small producers. Strategic planning of regional food security advocates integrating force of the region and creates, organizes, and directs the process of equitable distribution of resources at the territorial level. Building, implementing, and effective managing a unique model of regional development is a strategic task of the government. Management model should meet the main bases and principles of the National Strategy of Regional Development for 2020.

\section{REFERENCES:}

1. Knysh, Y. (2011). Genesis nature and content of the concept of "region" as an economic category. Efficient Economy, 11. URL: http://nbuv.gov.ua/UJRN/efek_2011_11_43

2. Voronkova, V. G. (2010). Regional-administrative management: a manual. Publishing house "Professional".

3. Manylich, M. I. (2004). The transformation of regional economic mechanism [monograph]. Chernivtsi Books. 
4. Matvienko, R. O. (2013). Economic system and its role in the regional space: specific elements. Actual problems of economy, 5, $152-155$.

5. Ulianchenko, A. V. (2014). Food security - the basis of national security. Congress World. URL: http://humanright.org.ua/ blogs/prodovolcha_bezpeka.

6. Chechel, A. (2000). State regulation of food security. Economy of AIC, 8, 73-76.

7. Coastal, V. K. (2011). Issues of Ukrainian food security. Economy of AIC, 5, 71-78.

8. Germanenko, L. M. (2015). Food security in the region as a prerequisite for national food security. Bulletin of the Eastern University of Economics and Management. Series: Economics and Management, 1, $20-27$.

9. Guidelines for the formation of regional development strategies (2002). Ministry of Economy and European Integration.

10. Osipov, V. M. (2014). Priorities for socio-economic development of Ukrainian context of modern regional policy. Prometheus. Transformation and prospects of development of local systems, 2 (44), 76-82.

11. Zhavoronkova, G. V. (2010). Strategic Regional Development. Problems of environmental biotechnology, 1, 26-31.

12. Fetisov, G. G. (2006). The regional Economy and Management: Textbook. INFRA-M.

13. Kozlovsky, S. V. (2012). Tools of food security and social protection crisis in terms of economies. Crimean Economic Bulletin, 1(01), 266-269.

14. Romanko, A. P. (2015). The concept of regional competitiveness and its features. Efficient Economy, 3. URL: http://www.economy.nayka.com.ua/ ?op=1\&z=3869

15. Panuhnyk, O. V. (2011). Methodical maintenance of strategic planning in the regions of Ukraine. Actual problems of Economy, 1(91), $152-157$.

16. Stepanova, K. V. (2016). Ukrainian Black Sea Euro-regional cooperation system. Socio-economic problems of the modern period in Ukraine. Institute of Regional Studies NAS of Ukraine, 3(119), 135-139. 
17. Gornyak, A. V. (2016). Estimation food security at regional level. Bulletin of the Odessa National University. Economy, 10(52), $17-21$.

\section{Information about the author:}

Shaposhnykov K. S.

Doctor of Economy, Professor, Head of the Black Sea Research Institute of Economy and Innovation, Ukraine Holovko O. P. Senior Research Scholar, Department of Macroeconomics and Public Administration, Black Sea Research Institute of Economy and Innovation, Ukraine 